\title{
EFFECT OF PITCH ON HEAT TRANSFER CHARACTERISTICS OF HELICAL COILS TO BE USED FOR BIOGAS PRODUCTION
}

\author{
Dawit . G. Gunjo' , P. K. Mahanta ${ }^{2}$, P. S. Robi ${ }^{3}$ \\ ${ }^{I}$ Department of mechanical engineering, Indian Institute of Technology (IITG), Guwahati, Assam, India \\ ${ }^{2}$ Department of mechanical engineering, Indian Institute of Technology (IITG), Guwahati, Assam, India \\ ${ }^{3}$ Department of mechanical engineering, Indian Institute of Technology (IITG), Guwahati, Assam, India
}

\begin{abstract}
Maintaining temperature and eliminating loss from anaerobic reactor highly improve the production of biogas .To achieve the required temperature inside the reactor supplying hot fluid externally using helical coil heat exchanger is required. Helical coil heat exchangers are widely used in industrial applications because they are more efficient as compared to straight tube type heat exchangers. This paper deals with the effect of pitch variation on the heat transfer characteristics (convective heat transfer coefficient, Nusselt number dean number heat removal rate etc.) of helical coil heat exchangers that can be used for supplying hot fluid to maintain the temperature of the reactor to achieve high biogas production. ANSYS 14.5 was used for the numerical investigation and the present study is done for three different coils of two turns having the same cross section and coil diameter but each coil having a different pitch. Modeling of the study was carried out based on the principles of thermodynamics, fluid mechanics, heat transfer and implementing the necessary boundary conditions. The results indicate that the heat transfer enhances with increasing pitch of the helical coil but with an increased pressure drop.
\end{abstract}

Keywords-Biogas, Helical coil heat exchanger, Pitch, Heat transfer characteristic

\section{INTRODUCTION}

Heat exchanger is a broad term associated with devices used for exchanging heat energy and are widely used in many engineering fields for the transport of heat from one fluid to the other. Application of heat exchanger include gas heating in waste heat recovery and gas cooling in intercooler of compressor, refrigerant evaporation and condensation in airconditioning, car radiators, liquid heat transfer in chemical and processing equipment, etc. Many factors are taken into account during the design of heat exchangers viz. thermal analysis, size, weight, structural strength, pressure drop, and cost.

Dittus and Boelter [1] derived a correlation to evaluate the heat transfer characteristics in straight tubes in which the Nusselt Number $(\mathrm{Nu})$ is governed by Prandtl Number $(\mathrm{Pr})$ and Reynolds Number (Re) under both laminar and turbulent regimes and is given as: $\mathrm{Nu}_{\mathrm{s}}=\mathrm{c} \mathrm{Re}^{\mathrm{a}} \operatorname{Pr}^{\mathrm{b}}$, where the subscript ' $\mathrm{s}$ ' is used for denoting $\mathrm{Nu}$ values for straight tubes and $\mathrm{a}, \mathrm{b}$, $\mathrm{c}$ are constants. The stated correlation is used for turbulent flow by considering the value $\mathrm{a}=0.8, \mathrm{c}=0.023$ and for $\mathrm{b}$ there are two values depending on whether the fluid is being heated or cooled. In case of heating, $b=0.4$ and for cooling, $\mathrm{b}=0.3$.

Seban and McLaughlin[2] disagreed with the correlation proposed by Jeschke to determine the heat transfer characteristics in case of coiled tubes given as $\mathrm{Nu}_{\mathrm{c}}=\mathrm{Nu}_{\mathrm{s}}[1+3.5(\mathrm{r} / \mathrm{R})]$, which depends on the curvature ratio $(\mathrm{r} / \mathrm{R})$, where ' $\mathrm{r}$ ' is the tube radius and ' $\mathrm{R}$ ' is the radius of curvature. They also obtained heat transfer coefficient in coiled tubes and straight tubes can be achieved and proposed a correlation for the heat transfer characteristics in the turbulent conditions given as $\mathrm{Nu}_{\mathrm{c}}=0.023 \operatorname{Re}^{0.85} \operatorname{Pr}^{0.4}(\mathrm{~d} / \mathrm{D})^{0.1}$, for $\operatorname{Re}(d / D)>6$, where ' $d$ ' is the tube diameter and ' $D$ ' is the coil diameter.

Prabhanjan et al. [3] conducted an experiment for heating liquids flowing through the tubes and observed that the helically coiled tube is more effective than a straight tube because the helical shape of the tube causes secondary flows to develop in the coil resulting in increased mixing of the fluid and faster heat transfer. It was also observed that the rise in the temperature of the fluid was more for the helical coil and the temperature rise decreased on increasing the mass flow rate because of lesser time the fluid gets to absorb the heat. Shirgire and Kumar [4] used a helically coiled heat exchanger against a straight tube heat exchanger for comparing the heat transfer characteristics considering steady state conditions. Hot water flowed through the tubes and cold water flowed on the outer side. For both counter and parallel flow the helical coil was found to be the most effective and compact than the straight tube heat exchanger. Also it was observed that the value of effectiveness was more for the counter flow type and increased when the cold water mass flow rate was increased but decreased when the hot water mass flow rate was increased. Mori and Nakayama [5] observed in case of coiled tubes that in the laminar region, the increase in heat transfer coefficient was proportional to the Reynolds number (Re) and they formulated a correlation to determine Nusselt number $\left(\mathrm{Nu}_{\mathrm{c}}\right)$ for coiled tubes as a function of the Dean (De) and straight tube Nusselt number $\left(\mathrm{Nu}_{\mathrm{s}}\right)$ given as: $\mathrm{Nu}_{\mathrm{c}}=\mathrm{Nu}_{\mathrm{s}}(0.1979) \mathrm{De}^{0.5}$, for $\mathrm{De}<2000$. They again later observed that under turbulent 
flow conditions in coiled tubes, the increase in heat transfer rate is not as significant as that under laminar flow conditions. At higher Reynolds Number (Re) and Prandtl Number (Pr) it was seen that the effect of turbulence become a significant factor over secondary flows. To make the heat transfer coefficient of coiled tubes comparable with those of straight tubes, correlation was made which calculated the value of Nusselt Number $(\mathrm{Nu})$ in terms of Re, Pr and Dean Number (De) in the turbulent regime and given as:

$$
N u_{c}=0.023\left\{1+\frac{0.061}{\left[\operatorname{Re}(d / D)^{2.5}\right]^{\frac{1}{6}}}\right\}(d / D)^{\frac{1}{12}} \operatorname{Re}^{0.833} \operatorname{Pr}^{0.4},
$$

for $\operatorname{Pr}>1$ and $\operatorname{Re}(d / D)>0.4$

Golmarz and Pesteei [6] studied the effects of Dean Number (De) and curvature ratio on heat transfer and pressure drop characteristics for laminar flow in case of a double pipe helical coil heat exchanger. The inner tube diameter of $0.009 \mathrm{~m}$ and outer tube diameter of $0.015 \mathrm{~m}$ having thickness of $0.0008 \mathrm{~m}$, radius of curvature $0.24 \mathrm{~m}$ and pitch $0.015 \mathrm{~m}$ were considered. It was observed that increasing the value of Dean Number for the inner and annulus part and also the curvature ratio increases the overall heat transfer coefficient (U). But with high value of Dean Number the pressure drop also increases and this pressure drop can be reduced by increasing the curvature ratio. R.K .Ashok [7] studied the effect of Dean Number (De) on heat transfer coefficients in a flat bottomed agitated vessel for Newtonian and NonNewtonian with different concentrations. Two helical coils of lengths $2.632 \mathrm{~m}$ and $2.8 \mathrm{~m}$ having internal diameter $4 \mathrm{~mm}$, external diameter $6.4 \mathrm{~mm}$ and curvature ratio of 0.02564 were taken and it was observed that as the agitation was increased by the impeller rotation speed the value of De increased thus resulting in increased heat transfer. The increase in De was seen at lesser agitation for lower viscosity fluids indicating that more viscous fluids required more agitation.

Mohammed Harith [8] conducted an experimental study on steady natural convection from helical coil tubes of two different curvature ratios $(d / D=0.1101$ and 0.0942$)$ with water as the bath liquid maintained at a constant temperature and air as the coolant fluid and without any mixing. It was found that when the curvature ratio and coolant flow rate increases the overall heat transfer coefficient and Nusselt number also increases. S.Ahire et al. [9] observed that the values of Nusselt Number $(\mathrm{Nu})$ and heat transfer coefficient increased with increasing Reynolds Number (Re). It was also observed that the Dean number (De) increased linearly with increasing Re which signifies increased turbulence for the hot fluid flowing inside the tubes. Thus, it results in the increase in the heat transfer rate as well as $\mathrm{Nu}$.

Effect of temperature on biogas production studied by $\mathrm{P}$. Vindis et al[10] compared the fermentation temperature for of three hybrid maize varieties in laboratory scale reactors under mesophilic (maintained at $37^{\circ} \mathrm{C}$ ) and thermophilic (maintained at $55^{\circ} \mathrm{C}$ ) conditions for biogas production. It was found that the volatile solid removal rate and yields were higher in thermophilic than in mesophilic condition. H.N. Gavala et al.[11] investigated the differences between mesophilic and thermophilic anaerobic digestion of primary and secondary sludge and the effect of the pretreatment process on these at $70^{\circ} \mathrm{C}$ regarding the methane potential and production rate. It was found that the concentration of volatile fatty acid (VFA), organic matter removal rate and methane production was higher in thermophilic digestion than in the mesophilic digestion. Young-Chae Song et al.[12] conducted a study to investigate the performance of thermophilic and mesophilic system It has been found that volatile faty acid removal rate were higher in thermophilic digester which leads better effluent quality, process stability and increased methane production. Kardos et al [13] compared anaerobic fermentation made on thermophilic and mesophilic temperatures by applying usual control parameters $(\mathrm{pH}$, volatile acid content, alkalinity, gas composition) and enzyme activity.it has been found that enzaymic activities were high in higher temperature thermophilic case.

Computational study was done by Chaves et al.[14] using CFD simulation to analyse the performance of tube in tube helically coiled heat exchanger (HCHE) made of copper coil having two and three turns respectively with water as the flowing liquid. It was observed that the performance efficiency of the 3 coil turns HCHE was more compare to 2 coil turns HCHE because of greater area of heat transfer as a result of one extra coil turn. Also it was seen that the efficiency of the HCHE increased when the hot fluid inlet temperature was increased. Kurnia et al. [15] investigated the heat transfer performance of coiled non-circular ducts of helical, conical and in plane spiral types. They compared their performance to straight ducts and observed that the helical ducts gave best performance for constant wall flux whereas for constant wall temperature it was spiral ducts. Helical ducts required highest pressure drop as compared to others because of the centrifugal force required to overcome the friction along the tube and to generate secondary flows.

Raj et al.[16] did numerical analysis of a helical coil heat exchanger (HCHE) of coil diameter $300 \mathrm{~mm}$, internal diameter $10 \mathrm{~mm}$ and thickness $1.35 \mathrm{~mm}$ and two different pitches $(30 \mathrm{~mm}, 60 \mathrm{~mm})$ using CFD. The value of $\mathrm{Nu}$ increased with increasing Dean Number (De) and it was observed that the heat transfer (removal) increased in both the coils with increasing the flow rate as it leads to an increase in the value of Nusselt Number $(\mathrm{Nu})$. Heat transfer was higher (almost twice) for the $60 \mathrm{~mm}$ pitch coil. But with increasing values of $\mathrm{Nu}$ and heat removed, the pressure drop was observed to rise and was greater for the $60 \mathrm{~mm}$ pitch coil. From the above reviews it is seen that heat transfer is more in helical coil heat exchanger as compare to straight tube and also biogas production highly depend on reactor temperature of the slurry. Most of the investigations have been conducted under isothermal wall conditions or constant heat flux conditions for simulation purpose. From their studies it can be concluded that the heat transfer coefficient in coiled tubes is higher than that in straight tubes. Also by reducing heat 
loss and maintaining the wall temperature from the wall of the reactor by supplying heat using helical heat exchanger can maintain heat loss hence increase the production of biogas. The schematic diagram of a complete setup shown in Fig.1.

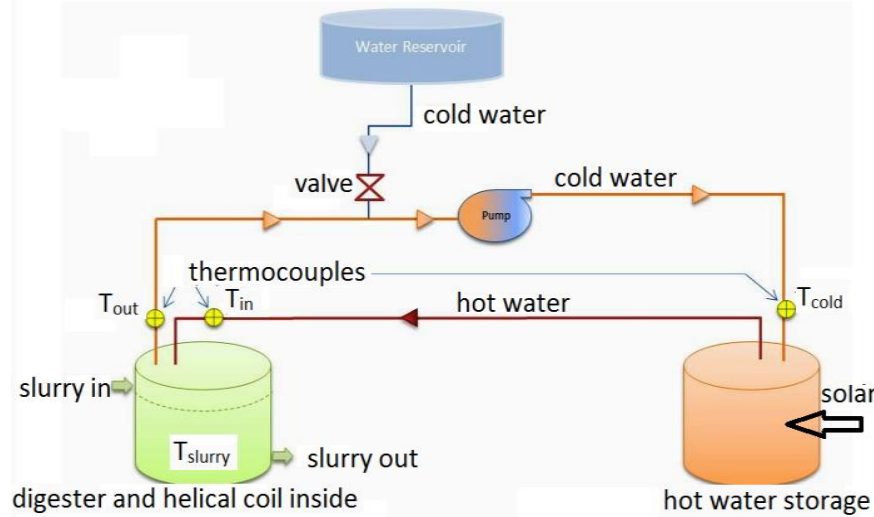

Fig.1: schematic diagram of complete setup

\section{HELICAL COIL FEATURES}

The important features of the helical coil are shown in Fig.2 below. The inner diameter of the tube is ' $d$ ' $(d=2 r)$, coil pitch circle diameter is ' $D_{c}$ ' $\left(D_{c}=2 R_{c}\right)$ and the distance between two consecutive turns is pitch, 'P'. The curvature ratio is given as $d / D_{c}$ or $r / R_{c}$, non-dimensional pitch, ' $\lambda$ ' is the ratio of pitch to length of one turn i.e. $\lambda=\mathrm{P} / \pi \mathrm{D}_{\mathrm{c}}$. De is a nondimensional number used to characterize the flow in helical pipe i.e. $D e=\operatorname{Re}\left(d / D_{c}\right)^{0.5}$, where Re is Reynolds Number.

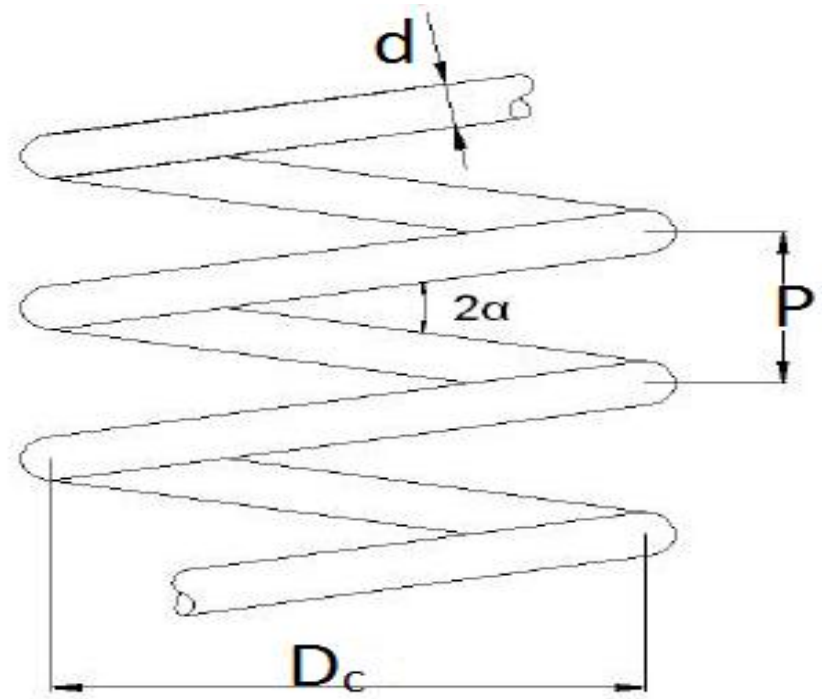

Fig.2: Coil features

\section{MATERIAL AND METHODS}

Helical coil heat exchanger made from copper. Modeling the copper coil using different pitch $(75 \mathrm{~mm}, 50 \mathrm{~mm}$ and $25 \mathrm{~mm})$ using ANSYS 14.5.Meshing of the modeled geometry using sweep meshing technique that gives better accuracy. Applying boundary condition. The boundary conditions used for this simulation are constant wall temperature of $308 \mathrm{~K}$. Water is considered to enter at a temperature of $330 \mathrm{~K}$ in all cases of inlet velocity for the velocity inlet boundary and leave the coil through pressure outlet boundary condition. For each pitch the flow rate of the water is varied from of $1 \mathrm{~m} / \mathrm{s}$ to $5 \mathrm{~m} / \mathrm{s}$ with an increment of $0.5 \mathrm{~m} / \mathrm{s}$.Interpreting the result. Drawing the graph that shows effect of dean number vs Nusselt number, pressure drop vs heat removed etc. and plotting both temperature and pressure contour. All the above steps clearly explained below.

\section{MODELING OF THE HELICAL COIL}

The geometrical model of the copper coil was done using ANSYS 14.5. Three different copper coil models were drawn having different pitches with other parameters fixed. Figure 3 shows the coil geometry for the $50 \mathrm{~mm}$ coil:

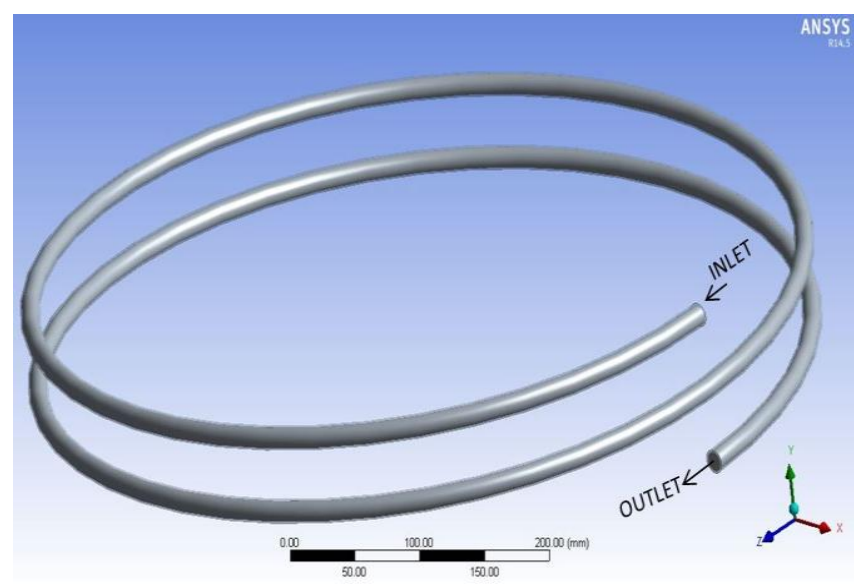

Fig. 3: 50mm pitch coil geometry

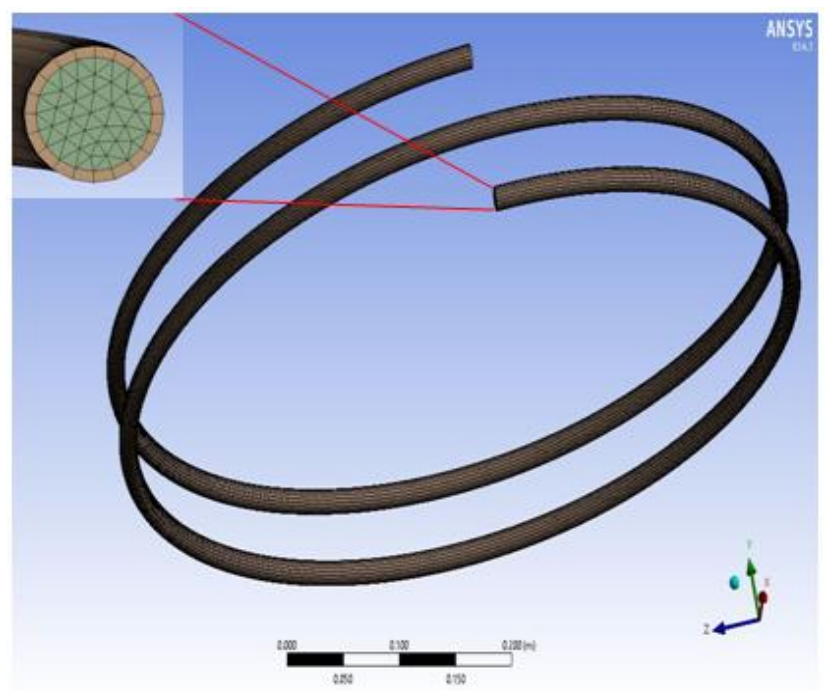

Fig. 4: $50 \mathrm{~mm}$ pitch coil mesh

\section{MESHING}

Meshing of the helical coil geometry was carried out using the sweep meshing method which yields more accurate results for curved bodies. The meshed geometry of the $50 \mathrm{~mm}$ pitch coil is shown in Fig. 4. The meshing was found satisfactory with a mesh quality reported as 0.925 and an aspect ratio of 3.04 . 


\section{GOVERNING EQUATIONS}

The simulation of 3-dimentional heat flow in the helical coil heat exchanger was done using ANSYS fluent by employing the governing equations stated below:

Continuity equation:

$$
\rho \frac{\partial u}{\partial x}+\rho \frac{\partial v}{\partial y}+\rho \frac{\partial \omega}{\partial z}=0
$$

Conservation of $\mathrm{x}$-momentum:

$$
\rho \frac{\partial u}{\partial t}+\rho u \frac{\partial u}{\partial x}+\rho v \frac{\partial u}{\partial y}+\rho \omega \frac{\partial u}{\partial z}=\mu\left(\frac{\partial^{2} u}{\partial x^{2}}+\frac{\partial^{2} u}{\partial y^{2}}+\frac{\partial^{2} u}{\partial z^{2}}\right)-\frac{\partial p}{\partial x},
$$

Conservation of y-momentum:

$$
\rho \frac{\partial v}{\partial t}+\rho u \frac{\partial v}{\partial x}+\rho v \frac{\partial v}{\partial y}+\rho \omega \frac{\partial v}{\partial z}=\mu\left(\frac{\partial^{2} v}{\partial x^{2}}+\frac{\partial^{2} v}{\partial y^{2}}+\frac{\partial^{2} v}{\partial z^{2}}\right)-\frac{\partial p}{\partial y},
$$

Conservation of z-momentum:

$$
\rho \frac{\partial \omega}{\partial t}+\rho u \frac{\partial \omega}{\partial x}+\rho v \frac{\partial \omega}{\partial y}+\rho \omega \frac{\partial \omega}{\partial z}=\mu\left(\frac{\partial^{2} \omega}{\partial x^{2}}+\frac{\partial^{2} \omega}{\partial y^{2}}+\frac{\partial^{2} \omega}{\partial z^{2}}\right)-\frac{\partial p}{\partial z},
$$

Conservation of energy:

$$
\nabla(\rho e \vec{V})=-p \nabla \vec{V}+\nabla(k \nabla T)+q+\phi,
$$

\section{BOUNDARY CONDITIONS}

The simulations of the 3-dimentional geometries of the helical copper coils were carried out under steady state conditions. For the analysis of turbulent flow, the standard $k$ $\varepsilon$ model is taken into consideration. The boundary conditions used for this simulation are constant wall temperature of $308 \mathrm{~K}$. Water is considered to enter at a temperature of $330 \mathrm{~K}$ in all cases of inlet velocity for the velocity inlet boundary and leave the coil through pressure outlet boundary condition. The three different pitches considered are $25 \mathrm{~mm}$, $50 \mathrm{~mm}$ and $75 \mathrm{~mm}$ and for each pitch the flow rate of the water is varied from of $1 \mathrm{~m} / \mathrm{s}$ to $5 \mathrm{~m} / \mathrm{s}$ with an increment of $0.5 \mathrm{~m} / \mathrm{s}$.

\section{SOLUTION METHOD}

The convergence criteria for obtaining the solution were given as 1e-8 for energy equation, 1e-6 for continuity, turbulence and momentum as well as the effect of gravitational force is applied in the analysis. Pressure velocity coupling was resolved using SIMPLE algorithm using skewness correction factor as 1. For pressure and momentum, linear discretization was done. For both turbulence kinetic energy and turbulence dissipation rate, power law was used.

\section{RESULTS AND DISCUSSIONS}

The numerical analyses are done for the helical coils for the three different pitches of $25 \mathrm{~mm}, 50 \mathrm{~mm}$ and $75 \mathrm{~mm}$ by varying the flow rate from $1 \mathrm{~m} / \mathrm{s}$ to $5 \mathrm{~m} / \mathrm{s}$ with increment of $0.5 \mathrm{~m} / \mathrm{s}$. The various heat transfer characteristics of the helical coils for all three pitches are plotted and compared. In the plots, the triangular readings are for the $75 \mathrm{~mm}$ pitch coil, the square readings are for the $50 \mathrm{~mm}$ pitch coil and the diamond shaped readings are for the $25 \mathrm{~mm}$ pitch coil. Figure 5 shows that the convective heat transfer coefficient varies directly with Nusselt Number, i.e. with increasing value of convective heat transfer coefficient the value of Nusselt Number increases linearly. The maximum value of convective heat transfer coefficient obtained is the highest for the $75 \mathrm{~mm}$ pitch coil having a value of $53000 \mathrm{~W} / \mathrm{m}^{2} \mathrm{~K}$. For the $50 \mathrm{~mm}$ pitch coil, the maximum value is $36000 \mathrm{~W} / \mathrm{m}^{2} \mathrm{~K}$ and the coil having $25 \mathrm{~mm}$ pitch has the least value with a maximum of $17800 \mathrm{~W} / \mathrm{m}^{2} \mathrm{~K}$.

As mentioned previously, the heat removed from the fluid taken in consideration increases with increasing value of Nusselt Number as shown in Fig. 6. It can be seen from the figure that the Nusselt Number as well as heat removed is highest for the $75 \mathrm{~mm}$ pitch coil and least for the $25 \mathrm{~mm}$ pitch coil with the $50 \mathrm{~mm}$ pitch coil having values in between these two. The maximum heat removed for the coil having $75 \mathrm{~mm}$ pitch is $43 \mathrm{~kJ}(41.75 \%)$, for the $50 \mathrm{~mm}$ pitch is $38 \mathrm{~kJ}(36.9 \%)$ and for the $25 \mathrm{~mm}$ pitch is $22.8 \mathrm{~kJ}(22.1 \%)$ which is $5 \%$ and $18 \%$ increment additionally, because of higher heat transfer area in helical coil heat transfer rate also high as compare to single plane coil. The relation of Nusselt Number with pressure drop is shown in Fig. 7. The Nusselt Number increases with an increase in the pressure drop. The highest pressure drop is observed in case of the $75 \mathrm{~mm}$ coil pitch having a maximum value of 51000 pa. The maximum pressure drop for the $25 \mathrm{~mm}$ pitch is 13100 pa and in the $50 \mathrm{~mm}$ pitch coil the maximum pressure drop is in between these two with a value of 33284 pa.

As expected, it can be interpreted from the above discussions so far that the maximum heat removal occurs at maximum pressure drop as can be seen in Fig. 8. It can be seen from the figure that the Nusselt Number as well as dean number is highest for the $75 \mathrm{~mm}$ pitch coil and least for the $25 \mathrm{~mm}$ pitch coil with the $50 \mathrm{~mm}$ pitch coil having values in between these two. The maximum Nusselt for the coil having $75 \mathrm{~mm}$ pitch is 700 , for the $50 \mathrm{~mm}$ pitch is 570 and for the $25 \mathrm{~mm}$ pitch is 110 for the same dean number as can be seen in Fig.9.

From the results we observe that the $75 \mathrm{~mm}$ pitch coil is better than the $50 \mathrm{~mm}$ and $25 \mathrm{~mm}$ pitch coil with respect to the heat transfer characteristics. This can be further supported with the help of the figures from Fig. 10 to Fig. 14 displaying the various contours of temperature and pressure of the coils. 


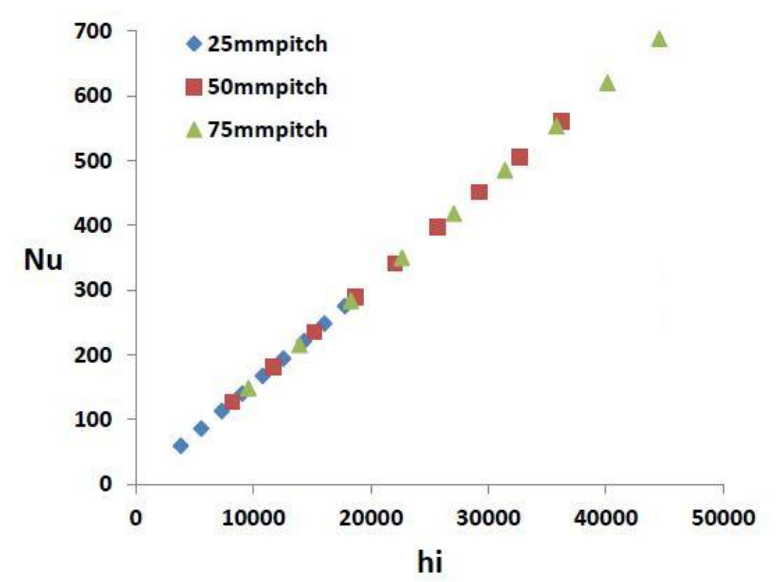

Fig. 5: Nusselt Number vs Convective heat transfer coefficient

The temperature contour along the wall for $25 \mathrm{~mm}, 50 \mathrm{~mm}$ and $75 \mathrm{~mm}$ pitch coils are shown from Fig. 10 to Fig. 12. It is evident from the figures that the temperature drop along the wall for the coil having $75 \mathrm{~mm}$ pitch is highest followed by the $50 \mathrm{~mm}$ pitch coil and the least for the coil with $25 \mathrm{~mm}$ pitch. In case of the coil with $75 \mathrm{~mm}$ pitch the temperature drop obtained along the wall is $20^{\circ} \mathrm{C}$, for the $50 \mathrm{~mm}$ pitch coil it is $17^{\circ} \mathrm{C}$ and for the $25 \mathrm{~mm}$ pitch coil it is $14^{\circ} \mathrm{C}$. This higher temperature drop along the wall for the $75 \mathrm{~mm}$ pitch coil is due its greater thermal loading as compared to the other two coils but faces a limitation of longer coil length and larger space requirement. This also results in most of the fluid at the outlet to be at a lower temperature for the $75 \mathrm{~mm}$ pitch coil as compared to the other two coils. This can be clearly observed by the Fig.13, Fig. 14 and Fig. 15 of the outlet shown for the $75 \mathrm{~mm}$ pitch and $50 \mathrm{~mm}$ pitch.

The pressure contours along the wall for the coils having $75 \mathrm{~mm}, 50 \mathrm{~mm}$ and $25 \mathrm{~mm}$ pitch are shown in Fig. 16, Fig. 17 and Fig. 18 respectively for an inlet velocity condition $1 \mathrm{~m} / \mathrm{s}$. It is seen from the figures that the pressure drop is highest with a value of $3750 \mathrm{pa}$ in case of the $75 \mathrm{~mm}$ pitch coil and the least for the $25 \mathrm{~mm}$ pitch coil with a value of $478 \mathrm{pa}$ and the pressure drop for the $50 \mathrm{~mm}$ pitch coil is intermediate between them with a value of 1750 pa.

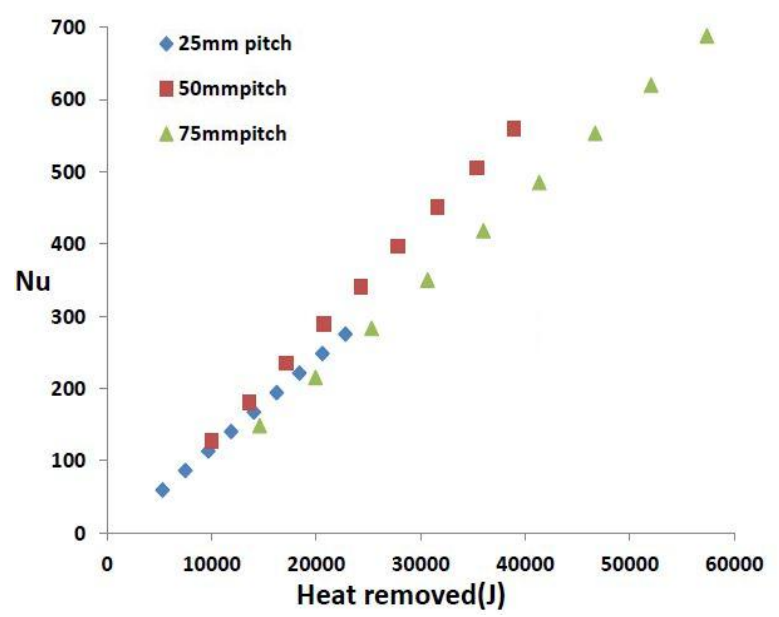

Fig. 6: Nusselt Number vs Heat removed

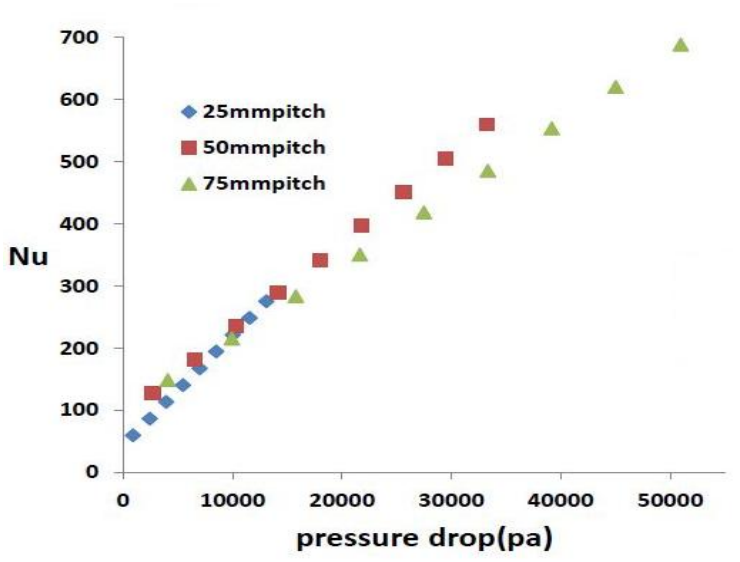

Fig. 7 Nusselt Number vs Pressure drop

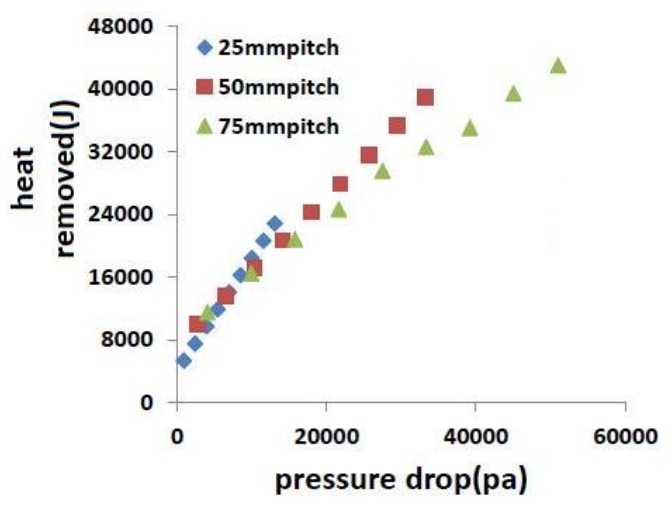

Fig8: Heat Removed vs Pressure drop

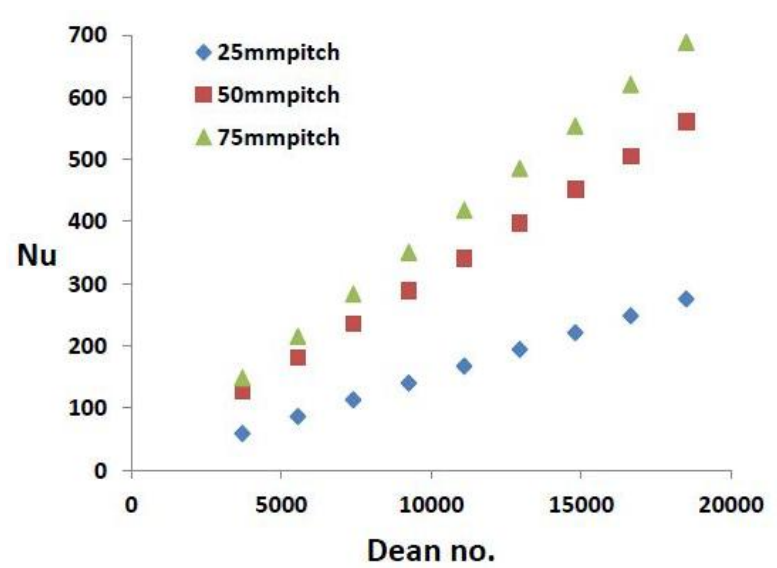

Fig. 9: Nusselt Number vs Dean Number.

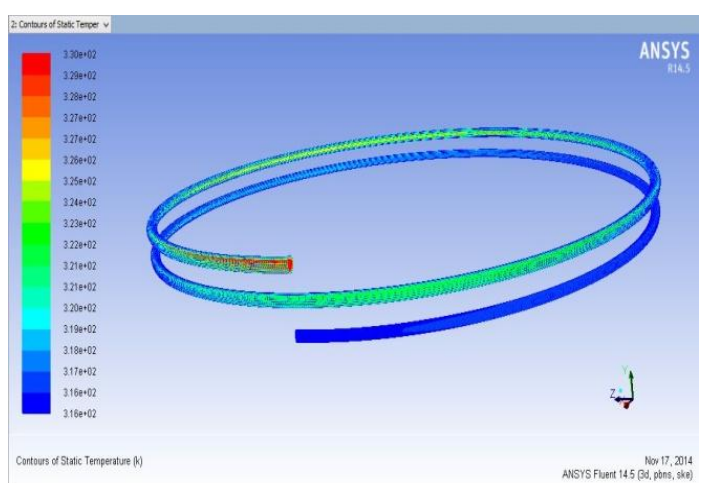

Fig. 10: Temperature contour for the $25 \mathrm{~mm}$ pitch coil 


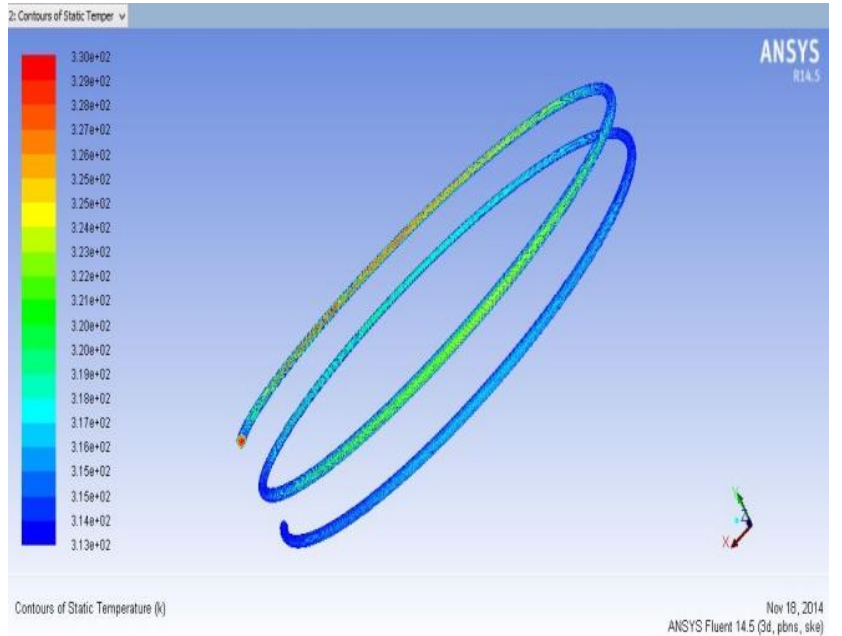

Fig. 11: Temperature contour for the $50 \mathrm{~mm}$ pitch coil

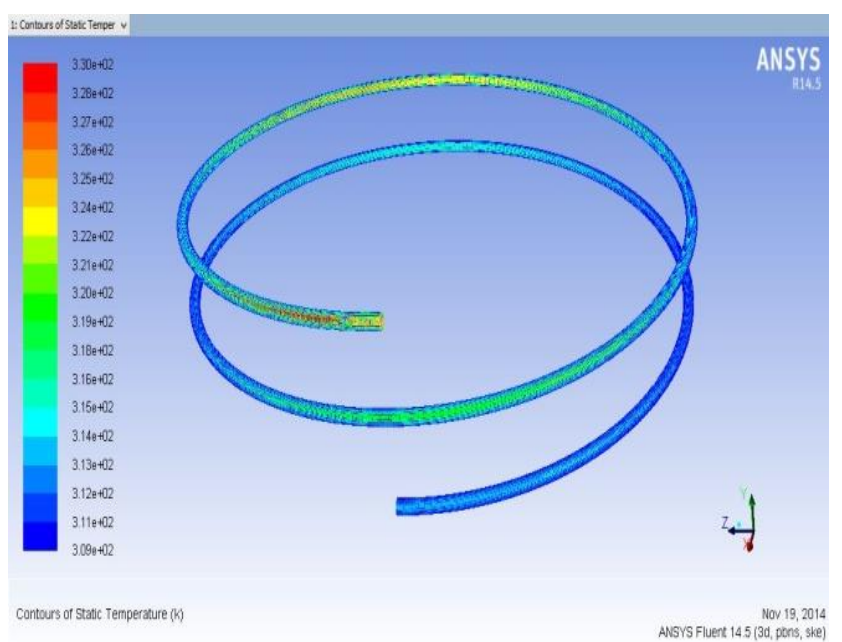

Fig. 12: Temperature contour for the $75 \mathrm{~mm}$ pitch coil

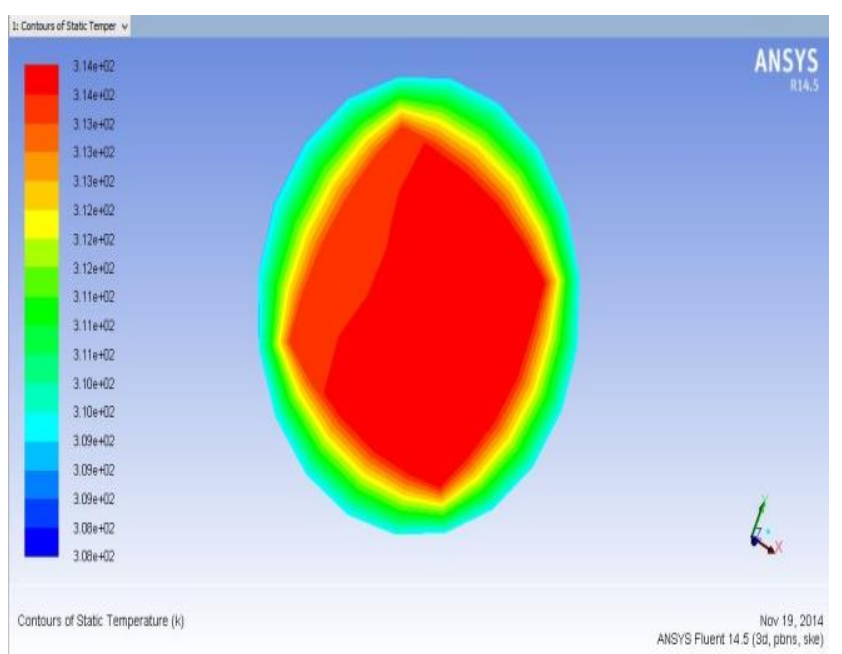

Fig. 13: Temperature contour for the $75 \mathrm{~mm}$ pitch coil at outlet

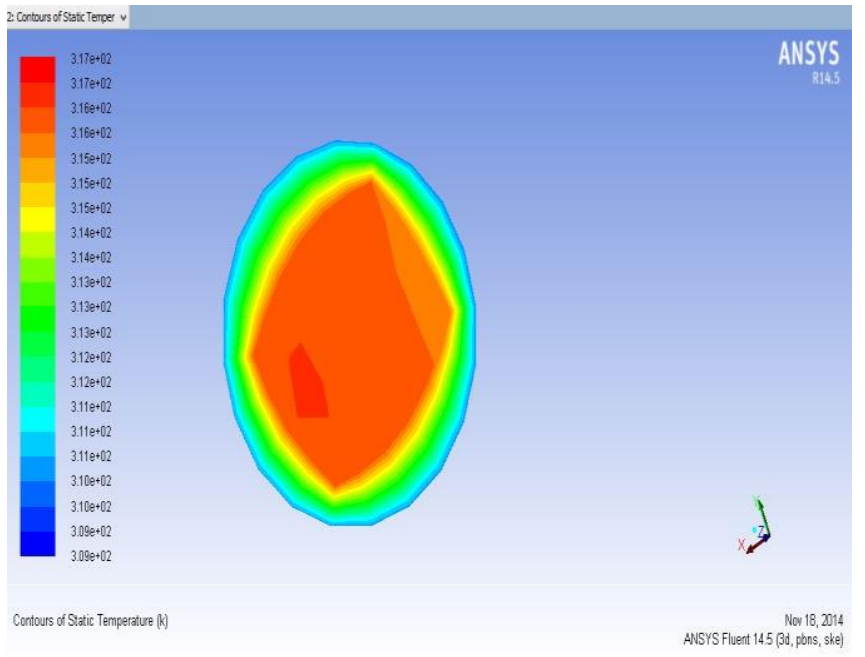

Fig. 14: Temperature contour for the $50 \mathrm{~mm}$ pitch coil at the outlet

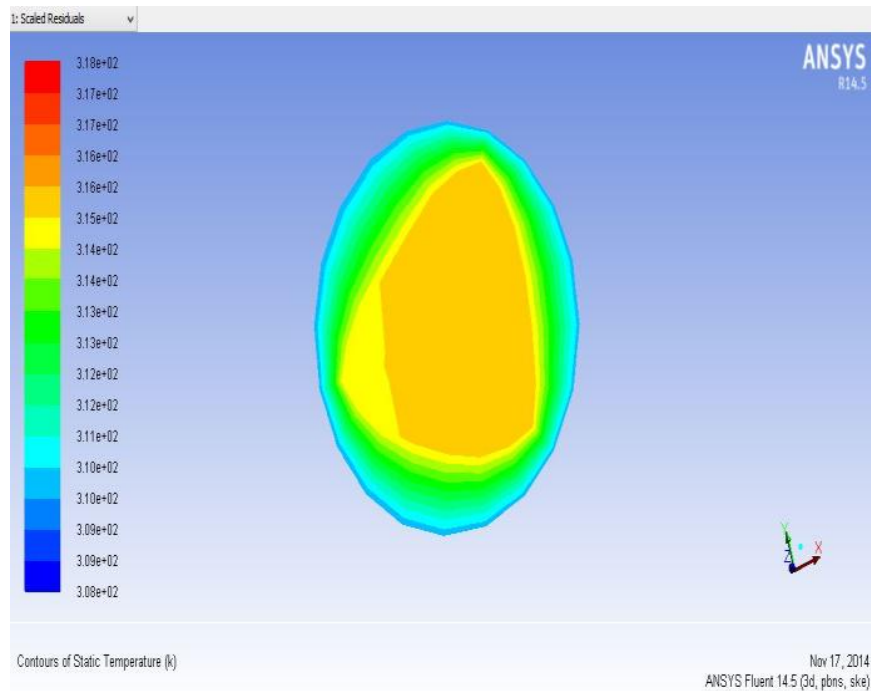

Fig. 15: Temperature contour for the $25 \mathrm{~mm}$ pitch coil at the outlet

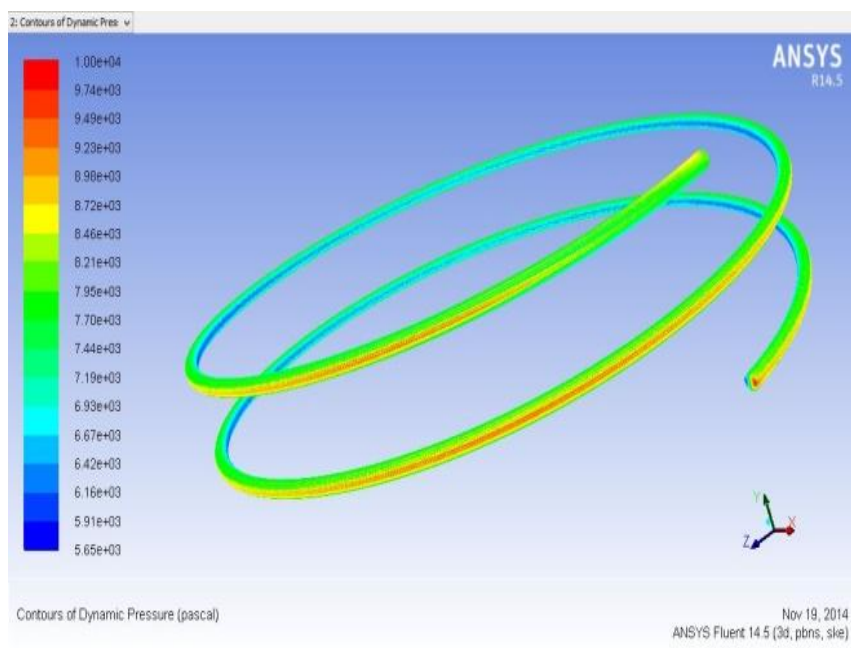

Fig. 16: Pressure contour for the $75 \mathrm{~mm}$ pitch coil 


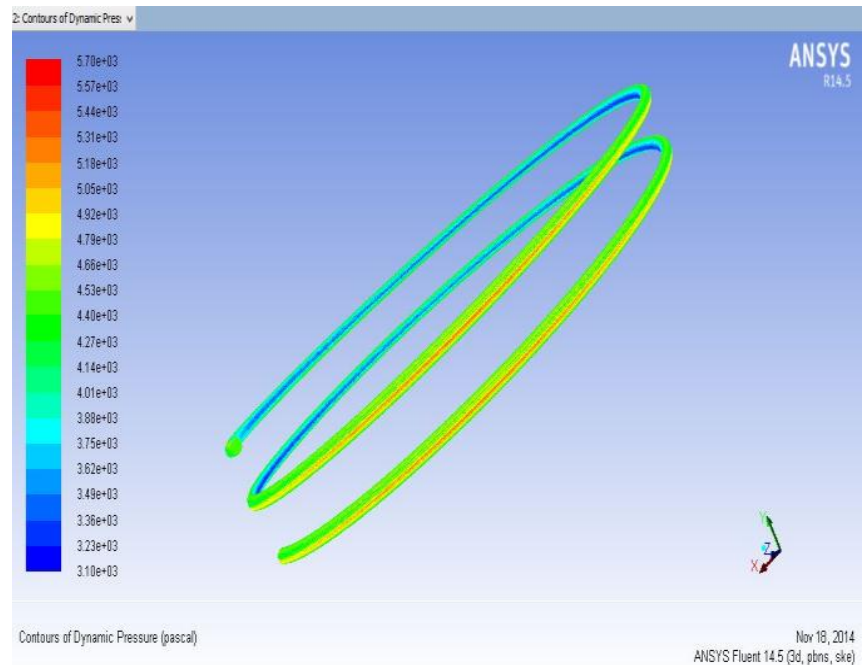

Fig. 17: Pressure contour for the 50mm pitch coil

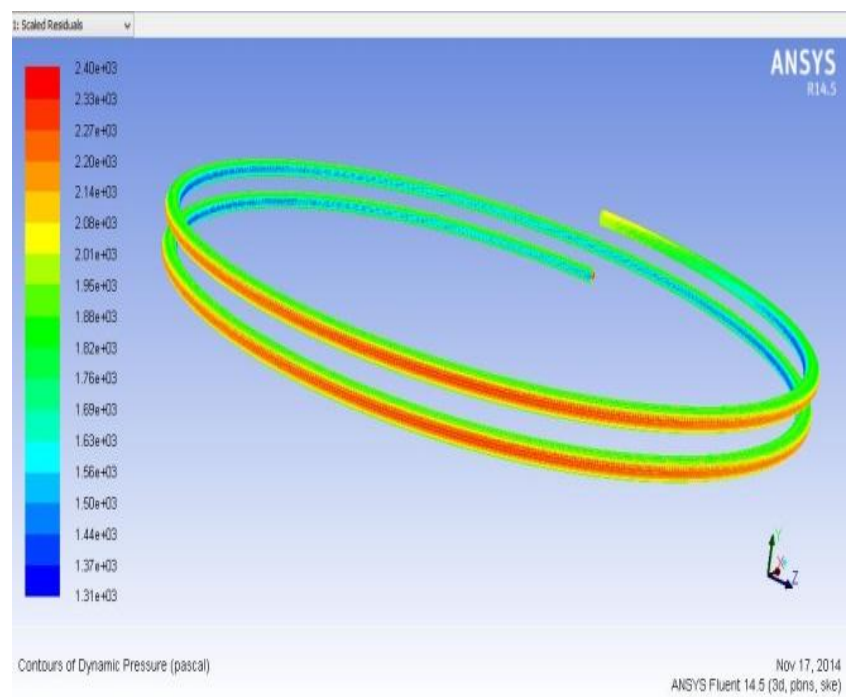

Fig. 18: Pressure contour for the $25 \mathrm{~mm}$ pitch coil

\section{RECOMMENDATIONS AND CONCLUSION}

As the number of turn increases the total surface area of the heat exchanger increase with appropriate pitch i.e the more increase the pitch pressure drop is high and less pitch also leads to low heat removal rate. For this particular work the number of turn is two because amount of temperature required is less $\left(35 c^{\circ}\right)$ enough to maintain mesophilic condition and also doesn't need new technology for manufacturing the helical coil.

This paper presents the analysis done on three helical coils focusing mainly on the effect of different coil pitch. The results obtained have led to the following conclusions regarding the heat transfer characteristics of these helical coils. The heat removed increases with increasing coil pitch and it is the highest for the coil having a pitch of $75 \mathrm{~mm}$ and least for the coil having a pitch of $25 \mathrm{~mm}$. The heat removed as well as the pressure drop increases with increasing Nusselt Number. Also, for a certain Dean Number the value of Nusselt Number is higher for higher pitch of the helical coil. The heat transfer characteristics for the coil having a pitch of $75 \mathrm{~mm}$ are better than the coils having pitch $50 \mathrm{~mm}$ and 25 $\mathrm{mm}$. The increment in heat transfer coefficient was high for the pitch change from $25 \mathrm{~mm}$ to $50 \mathrm{~mm}$ but on increasing the pitch beyond $50 \mathrm{~mm}$ the increment was moderate. This increased heat transfer comes with a limitation of higher pressure drop and more space requirements.

\section{NOMENCLATURE}

\begin{tabular}{|l|l|}
\hline$d$ & Inner diameter of tube $(\mathrm{mm})$ \\
\hline $\mathrm{r}$ & Inner radius of the tube $(\mathrm{mm})$ \\
\hline $\mathrm{d}_{0}$ & Outer diameter of tube $(\mathrm{mm})$ \\
\hline $\mathrm{D}_{\mathrm{c}}$ & Pitch circle diameter $(\mathrm{mm})$ \\
\hline $\mathrm{R}_{\mathrm{c}}$ & Pitch circle radius $(\mathrm{mm})$ \\
\hline $\mathrm{P}$ & Pitch $(\mathrm{mm})$ \\
\hline$\lambda$ & Non-dimensional pitch \\
\hline & Number of turns \\
\hline $\mathrm{Nu}$ & Nusselt number \\
\hline $\mathrm{Re}$ & Reynolds Number \\
\hline $\mathrm{Pr}$ & Prandtl Number \\
\hline $\mathrm{De}$ & Dean Number \\
\hline $\mathrm{U}$ & Overall heat transfer coefficient $\left(\mathrm{W} / \mathrm{m}^{2} \mathrm{~K}\right)$ \\
\hline $\mathrm{h}$ & Convective heat transfer coefficient $\left(\mathrm{W} / \mathrm{m}^{2} \mathrm{~K}\right)$ \\
\hline $\mathrm{Q}$ & Heat removed $(\mathrm{J})$ \\
\hline $\mathrm{k}$ & Thermal conductivity $(\mathrm{W} / \mathrm{m} \mathrm{K})$ \\
\hline $\mathrm{d} / \mathrm{D}_{\mathrm{c}}$ & Curvature ratio \\
\hline$\rho$ & Density $\left(\right.$ kg/m $\left.{ }^{3}\right)$ \\
\hline $\mathrm{Subscripts}$ \\
\hline $\mathrm{i}$ & Inner \\
\hline $\mathrm{o}$ & Outer \\
\hline
\end{tabular}

\section{REFERENCES}

[1]. F. W. Dittus, and L. M. K. Boelter, Heat transfer in automobile radiators of the tubular type. International Communications in Heat and Mass Transfer, vol.12, pp.3-22. 1985.

[2]. R. A. Seban, and E. F. McLaughlin, Heat transfer in tube coils with laminar and turbulent flow. International Journal of Heat and Mass Transfer,vol.6, pp.387-395, 1963.

[3]. D. G. Prabhanjan, T. J. Rennie, and G. V.Raghavan, Natural convection heat transfer from helical coiled tubes. International Journal of Thermal Sciences,vol.43, pp.359365, 2004.

[4]. N. D. Shirgire, and P. V. Kumar, Review on Comparative Study between Helical Coil and Straight Tube Heat Exchanger. IOSR Journal of Mechanical and Civil Engineering (IOSR-JMCE) e-ISSN, vol.2278, pp.1684, 2013. [5]. Y. Mori, and W. Nakayama,, Study on forced convective heat transfer in curved pipes, international Journal of Heat and Mass Transfer, Vol.8, pp. 67-82, 1965

[6]. T. P.Golmarz, and S. M. Pesteei, Investigation of Dean number and curvature ratio in a double-pipe helical heat exchanger, ISME, PP.1-5,2012.

[7]. R.K .Ashok, R.Bhagvanth and R. Ram, Effect of Dean Number on Heating Transfer Coefficients in an Flat Bottom Agitated Vessel, IOSR Journal of Engineering, vol. 2, pp. 945-951,2012.

[8]. Mohammed, H. Experimental Study of Free Convection in Coiled Tube Heat Exchanger. Tikrit Journal of Engineering Science (TJES), vol.18, pp.80-87,2011 
[9]. S. Ahire, P. Shelke, B. Shinde, and N. Totala, Fabrication and Analysis of Counter Flow Helical Coil Heat Exchanger, IJETT; vol. 15 pp.229-240, 2014.

[10]. Vindis, P., Mursec, B., Janzekovic, M., \& Cus, F. The impact of mesophilic and thermophilic anaerobic digestion on biogas production. Journal of achievements in materials and manufacturing Engineering, vol.36, pp.192-198,2009

[11]. Gavala, H. N., Yenal, U., Skiadas, I. V., Westermann, P., \& Ahring, B. K. Mesophilic and thermophilic anaerobic digestion of primary and secondary sludge. Effect of pretreatment at elevated temperature. Water Research, vol.37, pp.4561-4572,2003.

[12]. Song, Y. C., Kwon, S. J., \& Woo, J. H. Mesophilic and thermophilic temperature co-phase anaerobic digestion compared with single-stage mesophilic-and thermophilic digestion of sewage sludge. Water Research,vol.38,pp.16531662,2004.

[13]. Kardos, L., Juhász, A., Palkó, G. Y., Oláh, J., Barkács, K., \& Záray, G. Y.Comparing of mesophilic and thermophilic anaerobic fermented sewage sludge based on chemical and biochemical tests. Applied Ecology and Environmental Research,vol.9, pp.293-302,2011.

[14]. C.A. Chaves, D.R.F. de Castro, W. Q. Lamas, J. R. Camargo, and F. J.Grandinetti. Computational Fluid Dynamics (CFD) simulation to analyze the performance of tube-in-tube helically coiled of a heat exchanger. Scientific research and essay, vol. 9, pp. 181-188, 2014.

[15]. Kurnia, J. C., Sasmito, A. P., \& Mujumdar, A. S. Evaluation of the heat transfer performance of helical coils of non-circular tubes. Journal ofZhejiang University SCIENCE A, vol.12, pp.63-70.2011.

[16]. R. T. K. Raj , S. M. Kumar, C. A. Mathew, \& T. Elango, Numerical analysis of helically coiled heat exchanger using cfd technique, ARPN Journal of Engineering and Applied Sciences 2014; vol. 9, pp.3037,2014 .

\section{BIOGRAPHY}

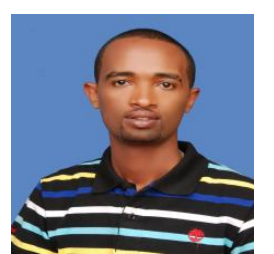

Dawit Gudeta Gunjo, Currently PhD Student at IIT Guwahati, Fluid and Thermal Science, Department Of Mechanical Engineering. I have done my Bachelor Degree in Mechanical Engineering from Mekelle University and Masters from Addis Ababa University. I have research interest in Heat Transfer, Solar Thermal Energy, Biogas and Other Types Of alternative energy. 